This is an author produced version of a paper published in Environmental Ethics.

This paper has been peer-reviewed but may not include the final publisher proof-corrections or pagination.

Citation for the published paper:

Erik Persson. (2016) Option Value, Substitutable Species, and Ecosystem Services. Environmental Ethics. Volume: 38, Number: 2, pp 165-181. http://dx.doi.org/10.5840/enviroethics201638214.

Access to the published version may require journal subscription. Published with permission from: Philosophy Documentation Centre.

Epsilon Open Archive http://epsilon.slu.se 


\section{Option value, substitutable species and ecosystem services}

\section{Introduction}

The value things and events (phenomena) have as means for promoting other phenomena with value usually go under the name instrumental value.

The phenomena that are promoted can in turn also have instrumental value through promoting other phenomena with value, and/or they can have value in the form of end value. ${ }^{1}$ That something has end value means that it has value as an end in its own right independently of whether it promotes anything else with value. What I here call 'end value' is sometimes referred to as 'intrinsic value', but the term 'intrinsic value' is given different meanings by different authors. ${ }^{2}$ Several attempts have been made to clear up the confusion, ${ }^{3}$ though In this paper I try to avoid the confusion by instead using the term 'end value'.

The instrumental value of a phenomenon is in part determined by the total end value it ultimately results in (directly or via a chain of other phenomena with instrumental value), and in part of how effective it is at promoting these phenomena. It is, however, also determined by the possible existence of alternative means to promote the same phenomena.

Some phenomena with end value can only be promoted in one way while others can be promoted in more than one way. This means that some phenomena that have instrumental value are substitutable in relation to a certain end value, while other phenomena with instrumental value are not. We therefore need to distinguish between substitutable and nonsubstitutable instrumental value. Since one instrumental value can be substitutable in relation to one resulting end value and non-substitutable in relation to another, categorising an instrumental value as substitutable or non-substitutable should always be done in relation to a specified end value. 
In general, the existence of alternative means for promoting the same end value reduces the instrumental value of each of the alternatives. This has implications for, among other things, the instrumental value of species in their roles as providers of ecosystem services. The concept of ecosystem services was invented to capture the instrumental value of species and ecosystems as providers of non-tradable services and not just of tradable goods. ${ }^{4}$ If a species is substitutable as a provider of ecosystem services, it will lead to an automatic reduction of its instrumental value, which in turn can lead to a situation where protection of the species will get lower priority. ${ }^{5}$

It is important, however, to also account for the fact that substitutability does not affect the value of the affected species in just one direction. The existence of alternative options can in fact be very valuable. In this article I show that the instrumental value of the options provided by a substitutable species can be very high. It cannot bring the total instrumental value of a substitutable species up to the same level as that of a non-substitutable species, all else being equal. It can, however, in many cases bring it up to a level that is higher than the total instrumental and end value of the projects that threaten the existence of the species.

Cod is, for example, a very popular food fish that due to its popularity has become threatened by over fishing. The awareness of this has led many consumers to buy other fish species instead. Does not the fact that this change was possible show that we do not have to worry too much about whether cod disappears as a food source, since there apparently are other fish species that can take over the same culinary niche? My suggestion is that the answer to this question is no. Instead, what this example shows, is that we should consider ourselves very lucky that we had this option and that this shows that the existence of options is very important. This in turn tells us that when determining the instrumental value of a substitutable species (whether in monetary terms or otherwise), the value of options have to 
be accounted for, and that it in many cases is important enough to play a decisive role in both management and policy decisions.

\section{Option value}

I will call the type of value something has as a provider of options, option value. I see option value as a form of instrumental value but do not exclude that it can also be an end value. There is for instance an ongoing discussion about whether freedom of choice can have end value, ${ }^{6}$ and since freedom of choice is sometimes defined in terms of a set of options, this discussion can partly also be applied on the notion of option value. Here I will, however, only discuss option value as an instrumental value, without making any assumptions regarding whether or not it can also be an end value.

The definition of 'option value' will thus be: 'The value something has because it provides an alternative way of promoting something else that has instrumental and/or end value.' I choose to talk about options instead of choices, partly to avoid getting stuck in the ongoing discussion about how to define 'choice', 'freedom of choice', etc., ${ }^{7}$ and partly because the word 'choice' conveys the impression that we talk about conscious acts. An important part of the option value of substitutable species is formed by their role in providing options for evolution and the function of ecosystems. Option value is thus not necessarily a matter of active choice.

Losing the only way of achieving a certain value is always worse than losing one of two or more options to achieve the same value. The option value of a substitutable phenomenon can therefore not bring its instrumental value up to the same level as that of a non-substitutable phenomenon in relation to the same end value, all else being equal. The option value can, however, increase the total instrumental value of a phenomenon enough to elevate it above some other competing value. This is important when for instance the 
achievement of a certain value can be achieved by the destruction of a species that can provide, but is substitutable in relation to, some ecosystem services. In cases like that it might be tempting to argue that the species can be sacrificed because it does not add any value that cannot be achieved without the species.

Some phenomena have both instrumental value and end value. Many things have instrumental value in relation to more than one phenomenon with end value. Many end values are promoted through a chain of phenomena with instrumental value where one phenomenon promotes another and so on until a phenomenon with end value is reached (if the phenomenon with end value also has instrumental value, the chain can continue even further to achieve another phenomenon with end value and so on). In some cases, the chain branches and one phenomenon with instrumental value gives rise to more than one phenomenon with end value.

\section{The option value of substitutable species}

Species in their roles as providers of ecosystem services are good illustrations of the practical relevance of option value. Species are examples of phenomena that can have both instrumental value and end value, and the same goes for individual members of the species. Eric Katz has pointed out that assigning value to individual beings based on their function in a larger system has the disadvantage of only focusing on their instrumental value while ignoring their end value (he uses the term 'intrinsic value'), and that this exclusive focus on instrumental value opens up for the substitutability problem. ${ }^{8}$ His criticism is aimed at holistic theories of environmental ethics, but it seems equally applicable to the ecosystem service concept. In principle I agree with his conclusion and I fully agree that we need to put more focus on the end value, not just the instrumental value, of both species and individuals. Since the ecosystem concept has become very influential with decision makers, I also think it 
is important, however, to try to mitigate the substitution problem in that context. Though I belong to those who find both species and individual non-human living beings valuable as ends, this is not agreed upon by everyone. The survival of most species therefore, in practice relies on them having instrumental value in relation to something else that human beings value as an end. This can be done by providing goods such as timber, food or energy, or by providing services such as pollination or carbon sequestration. ${ }^{9}$ The term 'ecosystem services' is sometimes limited to the provision of services and sometimes comprises the provision of goods as well as services. In this text it does not matter whether we include goods or not, the reasoning will be the same.

There are different opinions regarding the substitutability of ecosystem services, though there seems to be strong evidence that they in many cases are irreplaceable, and in most other cases, very difficult and costly to replace. ${ }^{10}$ Usually an ecosystem service does not stand or fall with one species, however. This means that, from an ecosystem service perspective, many species are substitutable. If one species disappears, others can be relied upon to provide the same service or play the same role in the ecosystem that supplies the service. According to one estimate, as much as $20-50 \%$ of the species in an ecosystem can disappear before the species loss constitutes any threat to the system. ${ }^{11}$

This kind of substitutability is sometimes used as an argument against the allocation of resources on conservation of species that cannot be shown to be irreplaceable as providers of an ecosystem service. I will argue, however, that substitutability can also add value to a species in the form of option value. This will not bring the value of substitutable species up to the same level as that of non-substitutable species, but it can in many cases make the substitutable species valuable enough from an ecosystem service perspective to elevate the instrumental value of these species above the competing value that would be realized by projects that threaten to cause the species to go extinct. 
The Millennium Ecosystem Assessment Report points out that the stability of ecosystems is, apart from its other values, also important for what they call "freedom of choice and action", defined as "opportunity to be able to achieve what an individual values doing and being". ${ }^{12}$ They argue that losing biodiversity is therefore also in many cases a loss of choices. ${ }^{13}$

Bryan Norton and Gretchen Daily reason along the same lines as the millennium assessors, but focus more directly on species. ${ }^{14}$ Norton points out that if we sacrifice a species for short-term gains, we also sacrifice what he calls "future options of the human race". ${ }^{15}$ The type of value that Daily, Norton and the Millennium assessors talk about are good examples of option value, since what have value in both cases are the options presented by the species.

The existence of alternative ways of providing ecosystem services is instrumentally valuable because things have a tendency to change. Both individual human beings and humanity as a whole, as well as the world around us, are subject to change. We do not know what preferences we, or coming generations, will have in the future. ${ }^{16}$ Also, we do not know what challenges we or coming generations will have to face in the future. ${ }^{17}$

One particular type of challenge that we face more and more regularly due to the increased extinction rate is in the form of a loss of species that perform ecosystem services. ${ }^{18}$ The existence of options in the form of more than one species that can perform the same service, or play the same role in the performance of the service, is a way of handling the loss of service providers.

The challenge can also be in the form of changing external conditions, for instance in the form of climate change. In these situations, it is important to have access to options that can provide or contribute to the provision of the same ecosystem service under different conditions. 
In a report to the Nordic Genetic Resource Center 2010, I showed that access to plant genetic resources of both cultivated and wild relatives of our most important food crops will for instance be absolutely vital for our ability to deal with the expected climate change. ${ }^{19}$ This is particularly true in light of the predicted increase in weather fluctuations within and between areas and seasons. This means that it is of great importance for both the individual farmer, and the society to increase the presently very low degree of genetic diversity among the crops that are grown for food today. Since it will be harder to predict exactly what kind of climate related disturbances (including everything from changes in precipitation to swarms of insects) that will affect a country, a region or a particular farm during a particular season, it is important to, so to speak, not put all your eggs in the same basket, but to grow a larger variety of crops that can survive different kinds of disturbances.

It might seem reasonable to qualify option value according to how good the option is at providing the service in question, just as instrumental value in general depends on the ability to promote a certain end value. If, for instance, two species are equally good at providing a service, they should have the same option value, while if one species is better than the other, the other species does provide an option but a less good option, and should therefore have a lower option value. On the other hand, options are valuable because things change. This is not least true in nature, and especially during the present era when human encroachments cause changes in nature at an unprecedented rate. This means that an option that is inferior just now might soon be superior. This is an important feature of option value and has to be accounted for. Since we cannot predict which options will be superior even in the near future and much less in a more distant future, I suggest that we do not grade options based on their present usefulness as options.

Having more than one option is a well-established and sensible risk management strategy. Having access to more options makes us less vulnerable if things do not go as 
expected. In agriculture, access to a variety of crops gives the farmer a larger set of options with regard to what to grow. Thereby, the farmer also becomes less vulnerable to changes, and gains control over his existence. We could argue in the same way concerning most uses of other species - as providers of food, timber, bio-energy, medicine, aesthetic experiences, etc. A larger selection of species gives us more options from which to choose. A species that has instrumental value and is substitutable will thereby also have option value through its contribution to our set of options from which to choose. It will therefore never be really redundant even if there are other ways of getting hold of the value that the species in question provides. If we lose a species that is instrumentally valuable but substitutable in relation to a certain end value, we have other ways of achieving that end value but we have none the less lost option value. The service that provides the value can be upheld even if one of the species that supply it disappears, but the number of different suppliers of the service, and therefore our set of options, has been reduced.

Species have option value in relation to our active choices of species as providers of different goods and services, but also in relation to their roles in the ecosystems. We can choose which species to use for instance for production of timber or for admiring through our binoculars during a hike, but most ecosystem services are indirect effects of how the ecosystems work. The species behind most ecosystem services are therefore not subject to active choice by us. We can still talk about them as having option value, however. When the ecosystem provides ecosystem services for us, the involved species have option value to us even though they do not directly provide us with any options to actively choose from. If two species are substitutable in relation to a certain service and one of them disappears or becomes significantly weakened, the other species will be able to take over its role as a supplier of the ecosystem service or its role in the ecosystem that provides the service even without any active interference by us. 


\section{The option value of money}

On the other hand, in many cases we lose species because of a process that generates something else that increases our set of options in another way or in another area. This means that option value will appear on both sides of the conflict.

The project that causes the extinction might for instance generate substantial amounts of money. Money represents a kind of universal instrumental value that can be transformed into many other phenomena with instrumental or end value. This means that money represents, in a way, the "ultimate option value". This makes money a very difficult competitor in all cases of trade-off when we value a large set of options. In today's society, it seems like this particular quality in money - its exchangeability into an incredibly large number of other values - has made it the most sought after commodity. We spend most of our lives pursuing, not things we value as ends, but money. ${ }^{20}$ Once we have the money we can exchange it for the things we really want. This looks like a detour, but instead of aiming directly for what we want, we go via money, not only because we know that we can get more of what we value by earning more money, but also because the money represents many different values. If we exchange a horse for a cow we have got a cow, but if we exchange a horse for money we can choose what to buy with the money. We can split it into many small sums and buy many less expensive things, or we can save it and add to it by selling more horses, and then buy something more expensive. We can sell to one person and use the money we get to buy from another person at another place and another time. Money is thus more flexible than goods in all of these ways. This means that just by exchanging a service or a commodity for money instead of another service or commodity and instead of keeping the original service or commodity, we tend to gain option value. Exchanging goods or services for money has been a manifestly successful way for people to increase their set of options, so 
successful even, that it has a tendency to make people forget about both the cases where the thing we want cannot be bought for money, and the cases where our options get diminished by the process.

\section{Substitutable species and the option value of money}

In light of what was just said about money as the ultimate option value, it might seem difficult to maintain that we, all in all, lose more option value than we gain by, so to speak, "transferring species into money", that is, by doing something that increases our economic wealth while causing species to go extinct.

However, in order for money to keep its option value, the things we like to buy with the money have to exist. The economic value of money is only as large as the value of the things one can buy with the money. This is why just printing more money without a corresponding increase in production only leads to a decrease in the economic value of the currency. In the same way, the instrumental value of money is determined by the end value it can provide for us, and the option value of money is only as great as the set of optional ways it provides for promoting phenomena with end value. If we cause a species to go extinct, we permanently remove one thing from the world and thereby make it impossible for anyone to utilise it. ${ }^{21}$ This means that when you make money in a way that causes a species to go extinct, you also decrease the number of options that the money represents (in the form of options for ecosystem services, food, material, aesthetic experiences, etc.) for everyone. Causing a species to go extinct therefore decreases the option value of money. The cod from the example in the introduction is a case in point. If we lose the cod, there is one less food item I can buy with my money, which means the option value of money has decreased.

Even so, one might argue that the decrease of the option value of money that results from the removal of a species is probably not very big considering how many other things 
you can get for your money, and especially considering that species and the ecosystem services provided by species are usually not bought and sold for money anyway (we can buy cod, but what about for instance the pollination service provided by wild bees?).

On the other hand, the services provided by the species are sometimes necessary for the maintenance and/or production of many things that are high in demand and that can be traded for money, such as food and wood (the pollination service provided by wild bees transfers into a large variety food crops that are traded on the market).

When substitutable species are sacrificed to increase someone's economic wealth, there is also another problem, and that is the decrease it causes in global option value. We need to distinguish between (I) increasing or decreasing option value on the personal scale (personal option value), that is, increasing or decreasing one's own access to existing options by, for instance, making or losing money, and (II) increasing or decreasing option value on the global scale (global option value) by increasing or decreasing the total number of alternative ways of promoting end values in the world. It is perfectly possible to increase one while decreasing the other. A fisherman might gain personal option value by transferring cod in the ocean into money in his wallet, but the global option value of the money in his and everyone else's wallet is diminished in the process. We also need to distinguish between (A) situations where someone increases personal option value by creating, or at least not decreasing, global option value, for instance by getting paid in exchange for something that she has created and (B) situations where someone increases personal option value in a way that decreases global option value, for instance by making money in a way that leads to irreversible destruction or depletion of something else (for example cod or any other species).

An increase in option value on the personal scale can thus increase or decrease option value on the global scale. An immediate increase in personal option value by means that decrease the global option value has the potential to decrease other people's personal option 
value and to limit everyone's chances of further increasing their personal option value. It can even turn the causing individual's immediate increase in personal option value into a loss in the long run.

Very often, however, the same project both creates and destroys options on the global scale. We might for instance cause extinction when we produce new consumer goods. Would it then not provide more option value on the global scale to produce more goods for the consumer to choose from than we lose in the form of extinct species? Would we for instance not create more option value on the global scale by producing ten new car models to choose from than by preserving one substitutable species?

I would say no for two reasons:

1. Extinction is irreversible, while a decision not to produce a new car model or any other new model of consumer goods is reversible. 2. Species and the ecosystem services they provide are the basis for many value chains. They thereby provide options for more values compared to new car models and other kinds of consumer goods that are usually found close to the end of their value chains.

\section{Extinction is irreversible}

When a species goes extinct it will be gone forever. It is sometimes argued that projects that destroy nature but increase economic growth may not be a big problem because it is always possible to use the money we gain to repair the damage. ${ }^{22}$ This is not possible when the destruction results in extinction. There are many things money cannot buy, ${ }^{23}$ but the most important of them might be extinct species. Several attempts have been made to resurrect extinct species, but so far none has been successful - and it might never happen.

An important complicating factor is that cloning is only possible if we have access to preserved DNA. In some cases, it is also necessary to find living relatives that can serve as 
surrogate mothers and maybe even as adoptive parents. Another limiting factor is that some species are so to speak "more than their genes". That is, some of the information that governs their behaviour is stored, not in their genes, but in their brains, and is passed on from generation to generation by the older animals showing the young. If the species goes extinct, this information will be irretrievably lost even if the information in the genes can be retrieved.

Even if it will eventually be possible to resurrect extinct species, there is no guarantee that a resurrected species can be reintroduced to its habitat and thereby take back its role in the ecosystem. In many cases, the species has gone extinct because its habitat has disappeared. This means that if we do not also recreate the habitat, which might involve the resurrection of several other species, there will be no future for the species in question even if it can be resurrected. In some cases it might be possible to keep the species in containment, but then it will have small chances to play any part in providing any ecosystem service.

Even the reintroduction of locally extinct species that are gone from one area but still exist in other areas have proven to be very costly and have a low success rate. ${ }^{24}$ Reintroduction of species that have become globally extinct, and therefore have not had any opportunity to evolve together with the ecosystem during the time they were gone, must reasonably be even more difficult and may even cause new problems in the ecosystem to which they are reintroduced. One important problem is that the environment may have changed while the species was gone. ${ }^{25}$ The niche that the species used to occupy might, for example, have been taken over by another species. ${ }^{26}$ This means that the resurrect species will be introduced to a system that it is no longer adapted to, or rather to a system that is no longer adapted to the species. This in turn increases the probability that the reintroduction will fail. It also means that if it works, it will inevitably interfere with the new order in the system, and it might affect species that have evolved in new directions after the extinction of 
the species we want to reintroduce. The reintroduced species might for example behave like an invasive species in the system. This in turn evokes new ethical questions. Is it, for instance, ethically acceptable to cause the extinction of an existing species in order to reintroduce a species that has gone extinct but has been resurrected?

Depending on what species concept one adheres to, it might in fact be impossible per definition to revive an extinct species. If we see species as individuals, ${ }^{27}$ or historical lineages,${ }^{28}$ instead of, for example, classes or natural kinds, a once extinct species will be gone forever even if it would be possible to create an exact replica of the species, just as a dead person would still be dead even if we could take her DNA and make a clone. The clone would have much in common with the dead person before she died, but it would not be the same person. The last objection might just be a real problem if we consider the end value of species, since the individuals in question cold play the same role in an ecosystem whether they count as the same species or not. The other objections, however, seem to be highly relevant for whether we can count on species revival to get back lost options or not, and it seems in conclusion that because of these and probably also other hitherto unknown problems, resurrecting species may never be a real alternative. The irreversibility of extinction is thus something we must consider a reality when we talk about possible contributors to ecosystem services.

There is (in general) no such thing involved when we lose money or abstain from producing another model of some consumer goods. If we miss an opportunity to make money, we can with few exceptions make money some other time and some other way. If a new car model or brand of soap is not made available on the market today, we can produce the car or the soap some other time if we choose to do so. If we cause the extinction of a species on the other hand, we can probably never get it back no matter how much money we have. That extinction is forever seems to be a very important reason for why species 
extinction is considered such a bad thing. ${ }^{29}$ In our case, it means that if a substitutable species goes extinct, option value is lost in a more fundamental way compared to when we abstain from making money or from introducing a new car model.

\section{Species are at the basis of many value chains}

So far we have been occupied with situations where the same end value can be promoted in more than one way, that is, where more than one value chain terminates in the same end value. On the other hand, some instrumental values can promote more than one end value. ${ }^{30}$ This means that one phenomenon with instrumental value can start several value chains terminating in different end values. This is also the case with phenomena that have substitutable instrumental value, in which case they are substitutable as providers of more than one other value. These value chains can in turn branch into even more value chains, eventually ending up in several different end values. Ecosystem services are often of this kind. Ecosystem services and the species that provide them are typically launching many value chains of which several have to do with our very survival, which in turn is necessary to realise most end values.

Substitutable species thus provide option value in relation to many other instrumental values that in many cases are substitutable in relation to other values, etc., until they emanate in a large number of different end values. This means that preserving the species will in effect provide options not just to the ecosystem in the form of a set of species that can take on the same function. They also help create options on several levels in relation to several other phenomena with instrumental value that in turn create options in relation to another level of resulting phenomena with instrumental values, and so on until we reach the end values. Because they eventually emanate in phenomena that have end value to us, all these options provide option value to us. Some ecosystem services are essential for our survival, which in 
turn is essential for the realisation of most things we value as ends. Species that provide options in relation to these ecosystem services provide options for options for options, etc. in relation to a large number of end values for all of us.

The more end value the resulting phenomenon has, the higher the instrumental value of the alternative means for promoting it, everything else being equal. This includes the option value for substitutable means. Creating a new car model to choose from creates option value for those who attach end value to cars, or to what the cars in their turn can promote (and who can afford the car in question). Preserving a species that constitutes an alternative way of promoting an ecosystem service that is essential for our survival creates option value for everyone who attaches end value to their lives, or to activities for which being alive is necessary.

Plants maybe most obvious example of how species can have a very high option value by being substitutable in relation to a certain ecosystem service that in turn promotes many different end values. Plants are in fact due to their role as primary producers at the bottom of most value chains. Birds who excavate and maintain cavities that can eventually be taken over by other species that in turn play different roles in the ecosystem, ${ }^{31}$ are typically found a bit higher up in the value chain but are still sufficiently close to the basis of the chains to be good examples of species that provide option value that has the ability to multiply as it transfers up the value chain. The higher up in the value chain we find a certain phenomenon, the fewer end values it typically provides options for, however. Phenomena that provide options on a more basic level, like species and ecosystems, typically have option value in relation to more phenomena with end value compared to phenomena very close to the end of the value chain, such as immediately consumable goods. Provision of options for a higher number of phenomena with end value potentially means provision of options for more total end value. 
This means that the total sum of option value created by a species that provides an alternative way of performing an ecosystem service, that in turn is essential to, or provides an option for, the promotion of a wide range of important end values, will with a wide margin outweigh the option value of having another car model, or ten new car models, or any other goods that might compete with the preservation of the species. It will also outweigh the instrumental value and end value of most projects that threaten the existence of the species.

It is in fact a tell-tale sign of many ecosystem services that they do promote many end values. A tree can be used to make wood that in turn can be used for a whole range of things that promote value for us, but it can also be left standing and promote other values, including oxygen, climate regulation, aesthetic experiences and habitat for other species.

The most obvious examples of ecosystem services that promote a multitude of end values are ecosystem services that are important for our survival, which in turn is a necessary prerequisite for the realisation of most things we value as ends. ${ }^{32}$ We could even go so far as saying that in spite of what we found above about money, money is not the ultimate option value after all. Phenomena that provide options for our survival is. Since providers of options for securing our survival enables the realisation of most of the things we value as ends, species that provide ecosystem services that provide options for our survival, must reasonably be very hard to beat as providers of option value.

The best illustration for our purposes is maybe pollination. Pollination performed by wild animals has turned out to be very important for our food production, which in turn is very important for our survival, which in turn is necessary for the realisation of most things we value as ends. The animals who perform this service in turn depend on other ecosystem services in the form of food, habitats, etc. Most of the services on each level are more or less substitutable, but the existence of more than one option for delivering each service is very valuable for the functioning of the entire web. The estimates of the importance of animal 
pollination differ. According to one source, almost all flowering plant species in the tropical rainforest and almost $90 \%$ of all flowering plants worldwide depend on pollination by animals. ${ }^{33}$ Another source reports that $65 \%$ of all flowering plants and $75 \%$ of all food crops in the world depend on pollination by animals. ${ }^{34}$ Either way, it seems clear that pollination provides quite a lot of options when it comes to food crops, that in turn provide optional food sources, that promote our survival.

In particular, wild bees are very important pollinators, ${ }^{35}$ not just in the tropics but all over the world. ${ }^{36}$ There are many pollinating bee species in the world, which means there is a large degree of redundancy, though different species differ in efficiency. One study shows for instance that for highland coffee, wild bees are more efficient pollinators than honey bees and solitary bees are more efficient than social bees. ${ }^{37}$ The order might differ between crops (and probably also between geographical regions), but it tells us that different bee species have different instrumental value as pollinators. As we noted earlier, however, the option value of a species should not depend on a species' relative efficiency in performing a particular service. The option value of social bees (to take the coffee example above) needs to be determined based on their role as options if the more efficient solutions (in this case, the solitary bees) disappear.

If we continue down the value chain we will find that different bee species prefer different species of flowers, and flowers of different height and flowers grouped in different ways (small groups vs. large groups). ${ }^{38}$ Some species are very picky when it comes to host species, which means that they have fewer options. In some cases, even one lost host species can be the nail in the coffin for an entire bee species. Even for more generalist species it is important not to diminish their options, however. Burkle et al. have shown that the abundance of bees in Illinois, USA has decreased significantly during the last 120 years. Generalist species that have a larger variety of food sources to choose from fared better than the 
specialists, which shows the value of options. Also the generalist species in Burkle et al.'s study were affected, however. They came to have fewer options, which made them more vulnerable to other changes in the environment. ${ }^{39}$ Preserving options for wild bees in the form of substitutable host plants and other important parts of their environment thus helps preserve viable populations of many different bee species, which in turn can pollinate a larger set of different crop species. The crop species in turn provide options for us in the form of what to grow and what food to eat, which can be very important both economically in order for the farmer to deal with changes in the environment, including climate change and new crop diseases, and ultimately for the consumers whose survival and prosper depends on a reliable access to food. This means that not just the bees but also the species that provide options for the bees to survive have option value for us in relation to all end values that presuppose our survival.

\section{Adding a non-anthropocentric perspective}

That substitutable species provide options to ecosystems and the evolutionary process does not mean that substitutable species have option value for ecosystems and the evolutionary process. It means, however, that by providing options to ecosystems and the evolutionary process they create option value for us. 'Us' does not necessarily refer only to human beings, however. Humans are not the only beings to whom things have value. All beings who have a perspective from which things can be good or bad (that is, all sentient beings) are beings to whom things can have value. Because substitutable species constitute options for providing ecosystem services to all living beings, substitutable species reasonably have option value also to non-human sentient beings.

Even from a strict anthropocentric perspective the option value provided by substitutable species is considerable. If we take on a wider perspective and include the option 
value substitutable species can have also for other sentient beings (as potential food sources for example), the total sum of option value provided by substitutable species will be even larger, not least considering that not only humans, but all sentient beings depend on ecosystem services for their survival, which as we have seen, in turn is a necessary prerequisite for the realisation of most end values.

\section{Summary and conclusions}

A phenomenon that has value as an end in its own right is said to have end value. A phenomenon that promotes other phenomena with value is said to have instrumental value. How high the instrumental value is, depends partly on the end value of the phenomena that it promotes directly or through a chain of successive phenomena with instrumental value. It also depends on how good the phenomenon in question is at promoting these phenomena and on the existence of alternative means for promoting them. If there are alternative ways to promote a certain phenomenon with end value, the instrumental value of each of the alternatives is lower than if there is only one way of promoting the end value. The existence of alternatives can also have value, however. I call this type of value option value.

The instrumental value of ecosystem services is typically very high, not least since they are important for our survival, which in addition to being highly valued for its own sake by most of us, also is necessary for the realisation of most other things we value as ends. This means that species that perform the services also have a high instrumental value. In most cases, ecosystem services can be performed by more than one species, however. This is sometimes used as an argument that we do not have to preserve all the species that can provide the service. Having access to alternative providers of important ecosystem services constitutes a high option value, however. In this paper, we have shown how species that are substitutable as providers of ecosystem services can have a very high option value that helps 
elevate the total instrumental value of these species to a level that is typically much higher than the total value of phenomena that might threaten the existence of the species.

\footnotetext{
${ }^{1}$ Let's assume that A promotes $B$ that promotes $C$ and that $C$ has value in its own right. Then $C$ has end value, while $\mathrm{B}$ has instrumental value in relation to $\mathrm{C}$ and $\mathrm{A}$ has instrumental value in relation to $\mathrm{B}$.

2 See:

Robin Attfield ‘Environmental Ethics and Intergenerational Equity’ Inquiry 41(1988): 207-222.
}

Eric Katz "Organism, Community, and the "Substitution Problem"” Environmental Ethics 7(1985): 241-256.

Charles M.C. Lee, Bhaskaran Swaminathan "What is the Intrinsic Value of the Dow?" The Journal of Finance 54 (1999): 1693-1741.

Millennium Ecosystem Assessment Ecosystems and Human Well-being - Biodiversity Synthesis (World Resources Institute, 2005).

Eric Plottu, Beatrice Plottu, "The Concept of Total Economic Value of Environment - A reconsideration within a hierarchical rationality” Ecological Economics 61 (2007): 52-61.

Wlodek Rabinowicz, Toni Rønnow-Rasmussen, "A distinction in value: Intrinsic and for its own sake"

Proceedings of the Aristotelian Society 20 (1999): 20-33.

Tom Regan, "Does environmental ethics rest on a mistake" The Monist 75 (1992): 161-182.

Holmes Rolston III, Environmental Ethics - Duties to and Values in The Natural World (Temple University Press, 1988).

for some different meanings of the term.

${ }^{3}$ E.g.

Rick O’Neil, “Intrinsic Value, Moral Standing, and Species” Environmental Ethics 19 (1997): 45f.

John O'Neill, "The varieties of intrinsic value" The Monist 75 (1992): 119f.

Wlodek Rabinowicz, Toni Rønnow-Rasmussen, "A distinction in value: Intrinsic and for its own sake" Proceedings of the Aristotelian Society 20 (1999): 20-33.

4 Robert Costanza, et al., "The value of the world's ecosystem services and natural capital" Nature 387 (1997): 253-260.

${ }^{5}$ As pointed out e.g. by Lilly-Marlene Russow "Why Do Species Matter?” Environmental Ethics 3(1981): 101112. She did not refer to ecosystem services, which is a concept that was "invented" later. Instead she talked about the suitability of grounding species preservation in the usefulness of the species to humans, which covers more or less the same cases.

${ }^{6}$ See e.g.

Tyler Cowen, Amihai Glazer, "Taxation and pricing when consumers value freedom" Social Choice and Welfare 24 (2005): 211.

Gretchen C. Daily, "Management objectives for the protection of ecosystem services" Environmental Science \& Policy 3 (2000): 335.

Keith Dowding, Peter John, "The value of choice in public policy” Public Administration 87 (2009): 219,223ff. Nicolas Gravel, "Ranking opportunity sets on the basis of their freedom of choice and their ability to satisfy preferences: A difficulty" Social Choice and Welfare 15 (1998): 371-382.

Martin van Hees, Marcel Wissenburg. 'Freedom and Opportunity' Political Studies 47 (1999): 67-82.

Martha C. Nussbaum, Creating Capabilities (Belknap Press 2011)

${ }^{7}$ see e.g.

Keith Dowding, "Choice: Its Increase and its Value" British Journal of Political Science 22 (1992): 301-14.

Keith Dowding, Peter John, "The value of choice in public policy" Public Administration 87 (2009): 219-233.

Johan E. Gustafsson, "Freedom of choice and expected compromise" Social Choice and Welfare 35 (2010): 6579.

Peter Jones, Robert Sugden, "Evaluating choice” International Review of Law and Economics 2 (1982): 47-65. Prasanta K. Pattanaik, Yongsheng Xu, “On preference and freedom” Theory and Decision 44 (1998): 173-198. Prasanta K. Pattanaik, Yongsheng Xu, "On diversity and freedom of choice” Mathematical Social Sciences 40 (2000): 123-130.

Eckehard F. Rosenbaum, "On measuring freedom” Journal of Theoretical Politics 12 (2000): 205.

Amartya Sen, "Freedom of Choice: Concept and Content" European Economic Review 32 (1988): $269-92$.

Robert Sugden, "Opportunity as a space for individuality: its value and the impossibility of measuring it" Ethics 113 (2003): 783-809. 
Martin van Hees, "Freedom of choice and diversity of options: some difficulties" Social Choice and Welfare 22 (2004): 253-266.

Martin van Hees, Marcel Wissenburg. 'Freedom and Opportunity’ Political Studies 47 (1999): 67-82.

8 Eric Katz "Organism, Community, and the "Substitution Problem"” Environmental Ethics 7 (1985): 241-256.

9 Gretchen C. Daily, "Management objectives for the protection of ecosystem services" Environmental Science \& Policy 3 (2000): 333-339.

Alison G. Power, "Ecosystem services and agriculture: tradeoffs and synergies" Philosophical Transactions of the Royal Society B 365 (2010): 2959-2971.

${ }^{10}$ See

Gretchen C. Daily, "Management objectives for the protection of ecosystem services" Environmental Science \& Policy 3 (2000): 333-339.

Anne H. Ehrlich, Paul R. Ehrlich, "Extinction - Life in Peril" in Suzanne Head and Robert Heinzman, eds., Lessons of the Rainforest (Sierra Club Books, 1990), pp.95-105.

Anne H. Ehrlich, Paul R. Ehrlich, "Extinction - Life in Peril" in Suzanne Head and Robert Heinzman, eds., Lessons of the Rainforest (Sierra Club Books, 1990), pp.95-105.

Zhongwei Guo, et al., "Ecosystem functions, services and their values - a case study in Xingshan County of China" Ecological Economics 38 (2001): 153.

Thomas E. Lovejoy, "Species Leave the Ark One by One", in Bryan G. Norton, ed., The Preservation of Species, (Princeton University Press, 1986), pp.13-27.

World Commission on Environment and Development, Our Common Future (Oxford University Press, 1987). for some different opinions.

11 Reed, F. Noss, "High-risk ecosystems as foci for considering biodiversity and ecological integrity in ecological risk assessments" Environmental Science \& Policy 3 (2000): 321-332.

${ }^{12}$ Millennium Ecosystem Assessment Ecosystems and Human Well-being - Biodiversity Synthesis (World Resources Institute, 2005: 19,25,30).

${ }^{13}$ Millennium Ecosystem Assessment Ecosystems and Human Well-being - Biodiversity Synthesis (World Resources Institute, 2005: 32).

14 Gretchen C. Daily, "Management objectives for the protection of ecosystem services" Environmental Science \& Policy 3 (2000): 333-339.

Bryan G. Norton, Why Preserve Natural Variety? (Princeton University Press, 1987: 63).

${ }^{15}$ Bryan G. Norton, Why Preserve Natural Variety? (Princeton University Press, 1987: 63).

16 Martin van Hees, Marcel Wissenburg. 'Freedom and Opportunity' Political Studies 47 (1999): 67-82: 75.

17 Gretchen C. Daily, "Management objectives for the protection of ecosystem services" Environmental Science \& Policy 3 (2000): 333-339.

${ }^{18}$ Gretchen C. Daily, "Management objectives for the protection of ecosystem services" Environmental Science \& Policy 3 (2000): 333-339.

Michael A. Huston, Greg Marland, "Carbon management and biodiversity" Journal of Environmental Management 67 (2003): 78.

${ }^{19}$ Erik Persson, Land use, Climate Change and Biodiversity (NordGen 2010).

${ }^{20}$ Money can of course be valued as an end but here we will only talk about its instrumental value and in particular its option value.

${ }^{21}$ Mary B Williams, "Discounting Versus Maximum Sustainable Yield" in R.I. Sikora, Brian Barry, ed., Obligations to Future Generations, (The White Horse Press, 1996), pp.173.

${ }^{22}$ See e.g. Marian Radetzki, Den gröna myten - Ekonomisk tillväxt och miljöns kvalitet, (SNS Förlag, 2002) p. 87.

${ }^{23}$ Michael J. Sandel, What money can't buy, (Farrar, Straus and Giroux, 2012).

24 Christian Gamborg, Peter Sandøe, "Conceptual uncertainty in nature management - illustrated by a case of reintroduction” in Kristina Blennow, ed., Uncertainty and Active Risk Management in Agriculture and Forestry (SLU, 2005), pp. 18f.

Terry L. Leitzell, "Species Protection and Management in an Uncertain World” in Bryan G. Norton, ed., The Preservation of Species, (Princeton University Press, 1986), p. 251.

Bryan G. Norton, "On the inherent Danger of Undervaluing Species", in Bryan G. Norton, ed., The Preservation of Species, (Princeton University Press, 1986), p. 121.

Lawrence B. Slobodkin, "On the Susceptibility of Different Species to Extinction: Elementary Instructions for Owners of a World" in Bryan G. Norton, ed., The Preservation of Species, (Princeton University Press, 1986), pp. $237 \mathrm{f}$

${ }^{25}$ Lawrence B. Slobodkin, “On the Susceptibility of Different Species to Extinction: Elementary Instructions for Owners of a World" in Bryan G. Norton, ed., The Preservation of Species, (Princeton University Press, 1986), pp. 237f. 
${ }^{26}$ Terry L. Leitzell, "Species Protection and Management in an Uncertain World" in Bryan G. Norton, ed., The Preservation of Species, (Princeton University Press, 1986), p. 251.

${ }^{27}$ as argued by e.g.

Michael T. Ghiselin, “A Radical Solution to the Species Problem” Systematic Zoology 23 (1974): 536.

David L. Hull, "On the Plurality of Species: Questioning the Party Line" in Robert A. Wilson, ed., Species -

New Interdisciplinary Essays (MIT Press, 1999), pp. 31ff.

${ }^{28}$ Kevin de Queiroz "The General Lineage Concept of Species and the Defining Properties of the Species

Category" in Robert A Wilson ed., Species - New Interdisciplinary Essays (MIT Press 1999), pp.49-89.

Bradley E. Wilson "A (Not-so-radical) Solution to the Species Problem" Biology and Philosophy 10 (1995): 229-356.

${ }^{29}$ See e.g. Thomas Elmqvist, Kerstin Johannesson, "Biologisk mångfald - inte bara arter” in Birgitta

Johansson, ed., Bevara arter - till vilket pris, (Formas 2005), p.46.

${ }^{30}$ Gretchen C. Daily "Management objectives for the protection of ecosystem services" Environmental Science \& Policy 3(2000): 333-339.

${ }^{31}$ Reed, F. Noss, "High-risk ecosystems as foci for considering biodiversity and ecological integrity in ecological risk assessments" Environmental Science \& Policy 3 (2000): 321-332.

${ }^{32}$ If we adhere to a mental state theory of value, this is true for all end values. It seems, though that even if we do not, we can safely say that it is true for most end values.

${ }^{33}$ K. S. Bawa, "Plant-pollinator interactions in tropical rain forests" Annual Review of Ecology and Systematics 21 (1990): 399-422.

Laura A. Burkle, John C. Marlin, Tiffany M. Knight "Plant-Pollinator Interactions over 120 Years: Loss of Species, Co-Occurrence, and Function" Science 339 (2013): 1611-1615.

${ }^{34}$ Alison G. Power, "Ecosystem services and agriculture: tradeoffs and synergies" Philosophical Transactions of the Royal Society B 365 (2010): 2959-2971.

${ }^{35}$ Lora A. Morandin, Mark L. Winston "Pollinators provide economic incentive to preserve natural

land in agroecosystems" Agriculture, Ecosystems and Environment 116 (2006): 289-292.

${ }^{36}$ For some examples, see

Lucas A. Garibaldi et al. "Wild Pollinators Enhance Fruit Set of Crops Regardless of Honey Bee Abundance" Science 339 (2013): 1608-1611.

Alexandra-Maria Klein, Ingolf Steffan-Dewenter, Teja Tscharntke "Fruit set of highland coffee increases with the diversity of pollinating bees" Proceedings of the Royal Society: Biological Sciences 270 (2003): 955-961.

Lora A. Morandin, Mark L. Winston "Pollinators provide economic incentive to preserve natural land in agroecosystems" Agriculture, Ecosystems and Environment 116 (2006): 289-292.

Jessica D. Petersen, Stephen Reiners, Brian A. Nault "Pollination Services Provided by Bees in Pumpkin Fields Supplemented with Either Apis mellifera or Bombus impatiens or Not Supplemented" PLOS ONE 8 (2013): 18.

${ }^{37}$ Alexandra-Maria Klein, Ingolf Steffan-Dewenter, Teja Tscharntke "Fruit set of highland coffee increases with the diversity of pollinating bees" Proceedings of the Royal Society: Biological Sciences 270 (2003): 955-961. Lucas A. Garibaldi et al. "Wild Pollinators Enhance Fruit Set of Crops Regardless of Honey Bee Abundance" Science 339 (2013): 1608-1611.

${ }^{38}$ Alexandra-Maria Klein, Ingolf Steffan-Dewenter, Teja Tscharntke "Fruit set of highland coffee increases with the diversity of pollinating bees" Proceedings of the Royal Society: Biological Sciences 270 (2003): 955-961.

${ }^{39}$ Laura A. Burkle, John C. Marlin, Tiffany M. Knight "Plant-Pollinator Interactions over 120 Years: Loss of Species, Co-Occurrence, and Function” Science 339 (2013): 1611-1615. 